\title{
New compounds and structures in the solid state
}

\author{
Edmund J. Cussen \\ DOI: $10.1039 /$ b612878p
}

This chapter reviews the 2006 literature on new compounds and structures in the solid state.

\section{Highlights}

A number of striking structures have been reported across the full compositional range of solid state compounds. The technical advances in characterisation techniques and innovative combinations of observations have permitted the determination of some structures of unparalleled complexity and highlights include the room temperature polymorph of $\mathrm{ZrP}_{2} \mathrm{O}_{7}$ and the most complex zeolite structure yet reported, TNU-9. A number of potentially useful new compounds have been identified including new phases for second harmonic generation and a new silicogermanate zeolite that exceeds the state-of-the-art as a catalyst for several industrially important processes. In addition to these studies the reports of a twodimensional ferromagnet or an air- and moisture-stable intermetallic phase that shows a strong resemblance to the host/guest chemistry of zeolites indicate that the structure of the solid state continues to be a source of challenging and interesting chemistry.

\section{Oxides}

The perovskite structure continues to yield new compounds that provide excellent models for understanding the effects of structure on physical properties. The perovskites $\mathrm{Ca}_{2} \mathrm{VMoO}_{6}$ and $\mathrm{Sr}_{2} \mathrm{VMoO}_{6}$ could be anticipated to show analogous behaviour to the cation-ordered semi-metallic phase $\mathrm{Sr}_{2} \mathrm{FeMoO}_{6}$. However, neither $\mathrm{Ca}_{2} \mathrm{VMoO}_{6}$ or $\mathrm{Sr}_{2} \mathrm{VMoO}_{6}$ show any evidence for cation ordering between vanadium and molybdenum and this allows $\mathrm{Sr}_{2} \mathrm{VMoO}_{6}$ to form a cubic perovskite $[\mathrm{Pm} \overline{3} m ; a=$ 3.91581(3) $\AA$ ] and $\mathrm{Ca}_{2} \mathrm{VMoO}_{6}$ to crystallise with a $\mathrm{GdFeO}_{3}$-type distortion of this structure [Pnma; $a=5.46613(8), b=7.6822(1), c=5.40335(7) \AA] .{ }^{1}$ Measurements of the magnetic susceptibility and electrical conductivity of these compounds are both characteristic of a fully delocalised electronic system and this consideration suggests that the oxidation states of the transition metals in these compounds exhibit non-integer oxidation values that are intermediate between $\mathrm{V}^{4+} / \mathrm{Mo}^{4+}$ and $\mathrm{V}^{3+} /$ $\mathrm{Mo}^{5+}$. The conductivity implies strong energetic overlap between the $t_{2 \mathrm{~g}}$ orbitals of both cations and suggests that a single crystal sample of $\mathrm{Sr}_{2} \mathrm{VMoO}_{6}$ should exhibit the highest conductivity of any metal oxide. By contrast, compounds in the system $\mathrm{Ba}_{2} \mathrm{LnMoO}_{6}$ show complete ordering between $\mathrm{Ln}^{3+}$ and $\mathrm{Mo}^{5+}$ over the octahedral

WestCHEM, Department of Pure and Applied Chemistry, The University of Strathclyde, Glasgow, Scotland, UK G12 8PT. E-mail: Edmund.Cussen@Strath.ac.uk; Fax: +44141548 4822; Tel: + 441415482797 
sites of the perovskite structure and hence crystallise with a rock-salt ordered pattern of $\mathrm{LnO}_{6}$ and $\mathrm{MoO}_{6}$ octahedra in a cubic lattice $[F m \overline{3} m]{ }^{2,3}$ These compounds show localised electronic behaviour with negligible electronic conductivity. ${ }^{2}$ Whilst most compounds do not show a well-defined magnetic transition at temperatures down to $2 \mathrm{~K}, \mathrm{Ba}_{2} \mathrm{NdMoO}_{6}$ undergoes antiferromagnetic ordering at $15 \mathrm{~K}$. Low temperature neutron diffraction experiments show that this anomalous behaviour arises from a structural distortion to triclinic symmetry $[I \overline{1} ; a=5.9790(2) \AA, b=5.9840(2) \AA$, $\left.\left.c=8.6024(2) \AA, \alpha=89.854(2)^{\circ}, \beta=90.056(5)^{\circ}, \gamma=90.003(5)^{\circ}\right)\right] .^{3}$ This structural transition is driven by a Jahn Teller distortion arising from the triply degenerate ground state of $\mathrm{Mo}^{5+}\left(4 \mathrm{~d}^{1}\right)$ in octahedral coordination geometry. This distortion is propagated through the structure and results in a negative thermal expansion of $0.32 \%$ in the c parameter on cooling from room temperature to $3.5 \mathrm{~K}$.

Jahn-Teller distortions are also observed in the Ruddlesden-Popper phases $\mathrm{La}_{x} \mathrm{Sr}_{2-x} \mathrm{Mn}_{1 / 2} \mathrm{Cu}_{1 / 2} \mathrm{O}_{4}(x=0.75,1,1.25,1.5) .{ }^{4}$ These structures are conceptually related to perovskite and can be considered to contain sheets of $\mathrm{Mn} / \mathrm{CuO}_{6}$ perovskite separated by layers of rock salt to yield highly anisotropic electronic properties. All compounds showed chemical disorder of copper and manganese over a single crystallographic site. The octahedrally coordinated site shows considerable distortion in the oxide anion position which increases with increasing $x$ up to a maximum for $\mathrm{La}_{1.5} \mathrm{Sr}_{0.5} \mathrm{Mn}_{1 / 2} \mathrm{Cu}_{1 / 2} \mathrm{O}_{4}$ which exclusively contains the Jahn-Teller active cations $\mathrm{Mn}^{3+}$ and $\mathrm{Cu}^{2+}$ on this position. For lower values of $x$ positional disorder in the apical oxide position indicates a local variation in structure to accommodate the random distribution of the Jahn-Teller inactive $\mathrm{Mn}^{4+}$ species on this site. The magnetic behaviour of these compounds is complex with some evidence of ferromagnetic coupling at high temperatures before the formation of antiferromagnetically-ordered phases at lower temperatures for $\mathrm{LaSrMn}_{1 / 2} \mathrm{Cu}_{1 / 2} \mathrm{O}_{4}, \operatorname{PrSrMn}_{1 / 2^{-}}$ $\mathrm{Cu}_{1 / 2} \mathrm{O}_{4}$ and $\mathrm{NdSrMn} \mathrm{Mn}_{1 / 2} \mathrm{Cu}_{1 / 2} \mathrm{O}_{4}$.

A number of new lithium containing garnet phases have been reported ${ }^{5,6}$ and are the subject of detailed study due to the observation of fast $\mathrm{Li}^{+}$conduction, $\approx 10^{-5} \mathrm{~S}$ $\mathrm{cm}^{-1}$, in this structure. Neutron diffraction has been used to generate the first precise description of the garnet phases $\mathrm{Li}_{5} \mathrm{La}_{3} \mathrm{Ta}_{2} \mathrm{O}_{12}$ and $\mathrm{Li}_{5} \mathrm{La}_{3} \mathrm{Nb}_{2} \mathrm{O}_{12}$ that contain an additional two lithium cations beyond the conventional garnet stoichiometry. ${ }^{7}$ The compounds crystallise in the space group $[\operatorname{Ia} \overline{3} d]$ that is commonly observed for garnets albeit with considerably expanded lattices, $a \approx 12.80654(11) \AA$ for $\mathrm{Li}_{5} \mathrm{La}_{3}$ $\mathrm{Ta}_{2} \mathrm{O}_{12}$. This expansion opens additional octahedral interstitial sites in the structure and the lithium partially occupies these distorted sites in addition to a partial occupancy of the conventional tetrahedral site. This occupational disorder suggests possible mechanisms for the observed fast $\mathrm{Li}^{+}$conduction.

Ionic mobility has been exploited to derive new materials from the RuddlesdenPopper phase $\mathrm{K}_{2} \mathrm{La}_{2} \mathrm{Ti}_{3} \mathrm{O}_{10}$. This compound contains a triple layer of perovskite separated by rock salt layers that contain apparently mobile $\mathrm{K}^{+}$and reaction of this material with $\mathrm{PPh}_{4} \mathrm{Br}$ in the solid state leads to formation of $\mathrm{K}_{2} \mathrm{O}$ and the stability of this product drives the formation of novel layered phases. ${ }^{8}$ The product of this reaction is controlled by the reaction stoichiometry as shown below:

$$
\begin{gathered}
\mathrm{K}_{2} \mathrm{La}_{2} \mathrm{Ti}_{3} \mathrm{O}_{10}+\mathrm{PPh}_{4} \mathrm{Br} \rightarrow \mathrm{KLa}_{2} \mathrm{Ti}_{3} \mathrm{O}_{9.5}+\mathrm{KBr}+\frac{1}{2} \mathrm{PPh}_{3} \mathrm{O}+\frac{1}{2} \mathrm{PPh}_{3}+\frac{1}{2} \mathrm{Ph}_{2} \\
\mathrm{~K}_{2} \mathrm{La}_{2} \mathrm{Ti}_{3} \mathrm{O}_{10}+2 \mathrm{PPh}_{4} \mathrm{Br} \rightarrow \mathrm{La}_{2} \mathrm{Ti}_{3} \mathrm{O}_{9}+2 \mathrm{KBr}+\mathrm{PPh}_{3} \mathrm{O}+\mathrm{PPh}_{3}+\mathrm{Ph}_{2}
\end{gathered}
$$

Reaction of the metal oxide product of either of these reactions with $\mathrm{KNO}_{3}$ at $T \leq 600{ }^{\circ} \mathrm{C}$ leads to reformation of the $\mathrm{K}_{2} \mathrm{La}_{2} \mathrm{Ti}_{3} \mathrm{O}_{10}$ starting material. This 
sequence of reactions initially converts the Ruddlesden-Popper starting material to a Dion-Jacobson phase where the interlayer rock salt pattern is replaced by a $\mathrm{CsCl}$ motif which requires translation of the $\mathrm{La}_{2} \mathrm{Ti}_{3} \mathrm{O}_{10}$ block. Further extraction of $\mathrm{K}_{2} \mathrm{O}$ translates these blocks again to give the original arrangement but with the interlayer region vacant and heavily distorted $\mathrm{TiO}_{6}$ octahedra.

A low temperature topotactic synthetic process has also yielded the unusual layered phase $\mathrm{LiTiNbO}_{5}{ }^{9}$. This was formed by ion exchange of $\mathrm{Li}^{+}$for $\mathrm{H}^{+}$in the layered phase $\mathrm{HTiNbO}_{5}$, itself formed by ion exchange from the $\mathrm{KTiNbO}_{5}$ parent. $\mathrm{HTiNbO}_{5}$ contains infinite layers of $\mathrm{TiNbO}_{5}$ units containing metal oxide octahedra linked by a mixture of edges and corners. Reaction of this compound with the eutectic composition of $\mathrm{LiOH}$ and $\mathrm{LiNO}_{3}$ at $200{ }^{\circ} \mathrm{C}$ gave $\mathrm{LiTiNbO}_{5}$. The structure of this product maintains the sheets of the parent phase with an adjustment in the arrangement of the layers as shown in Fig. 1. The layered structure allows the reversible electrochemical intercalation of 0.8 lithium per formula unit.

A new series of layered phases have been identified based on intergrowth of perovskite and $\mathrm{CdI}_{2}$ structure types to give compositions $\mathrm{Ba}_{n+1} \mathrm{Co}_{n} \mathrm{O}_{3 n+3}\left(\mathrm{Co}_{8} \mathrm{O}_{8}\right) .{ }^{10}$ The $n=1$ and $n=2$ phases $\mathrm{Ba}_{2} \mathrm{Co}_{9} \mathrm{O}_{14}$ and $\mathrm{Ba}_{3} \mathrm{Co}_{10} \mathrm{O}_{17}$ both crystallise in the space group $R \overline{3} m[a=5.6958(4), c=28.909(4) \AA$ and $a=5.6901, c=35.937(5) \AA$ for $n=1$ and $n=2$, respectively]. These structures can be considered to be composed of close packed layers of either $\mathrm{BaO}_{3}$ or oxide anions with cobalt occupying octahedral interstitial sites; the former leads to $n$ perovskite layers and the latter leads to the $\mathrm{CdI}_{2}$ structure. The structures are complicated with additional cobalt occupying the tetrahedral interstices at the interface between these two structure types. Both compounds undergo antiferromagnetic transitions around $50 \mathrm{~K}$.

The series $\mathrm{RuSr}_{2} \mathrm{Nd}_{1.8-x} \mathrm{Y}_{0.2} \mathrm{Ce}_{x} \mathrm{Cu}_{2} \mathrm{O}_{10-\delta}$ has been prepared by careful control of composition, temperature and oxygen partial pressure during synthesis. ${ }^{11}$ These compounds contains square pyramidal coordinated copper sites separated by corner sharing with a central $\mathrm{RuO}_{6}$ octahedron. The $\mathrm{Ru}$ and $\mathrm{Cu}$ sublattices undergo separate magnetic ordering transitions at 160 and $60 \mathrm{~K}$, respectively and negative magnetoresistance is observed below the $\mathrm{Ru}$ ordering temperature. The magnetoresistance shows a strong correlation with the doping level in $\mathrm{RuSr}_{2}$ $\mathrm{Nd}_{1.8-x} \mathrm{Y}_{0.2} \mathrm{Ce}_{x} \mathrm{Cu}_{2} \mathrm{O}_{10-\delta}$ which can be further tailored by the choice of lanthanide;

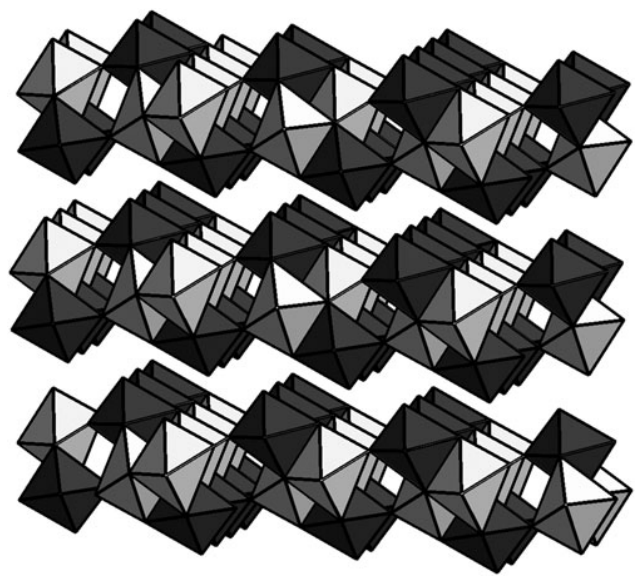

Fig. 1 The $\left[\mathrm{TiNbO}_{5}\right]^{-}$sheets observed in $\mathrm{LiTiNbO}_{5}$. Light and dark grey shading indicates that the oxide octahedra are rich in $\mathrm{Ti}$ and $\mathrm{Nb}$, respectively. ${ }^{9}$ 
substitution of $\mathrm{Nd}^{3+}$ by a small lanthanide causes a unprecedented change from negative to positive magnetoresistance driven by the progressive reduction in cation size.

Treatment of the Ruddlesden-Popper phase $\mathrm{YSr}_{2} \mathrm{Mn}_{2} \mathrm{O}_{7}$ with sodium hydride has yielded a topotactically reduced phase $\mathrm{YSr}_{2} \mathrm{Mn}_{2} \mathrm{O}_{5.43(3)}$ which can be reacted with the starting material to give the intermediate phases $\mathrm{YSr}_{2} \mathrm{Mn}_{2} \mathrm{O}_{6.54(3)}$ and $\mathrm{YSr}_{2} \mathrm{Mn}_{2} \mathrm{O}_{5.96(3)}{ }^{12}$ The perovskite double layer and tetragonal symmetry (I4/ $\mathrm{mmm}$ ) of the starting material is preserved throughout these reactions. For small levels of oxide deficiency the anion vacancies are distributed evenly through the three crystallographically distinct oxide positions, but as the anion vacancy concentration is increased a clear preference for vacancies in the $\mathrm{MnO}_{2}$ layer of the perovskite block emerges. This is driven by the inflexible bonding requirements of $\mathrm{Sr}^{2+} / \mathrm{Y}^{3+}$ compared to the variable requirements of $\mathrm{Mn}^{2+} / \mathrm{Mn}^{3+} / \mathrm{Mn}^{4+}$. The behaviour of the related triple layer perovskite $\mathrm{LaSr}_{3} \mathrm{Fe}_{1.5} \mathrm{Co}_{1.5} \mathrm{O}_{10.1}$ has also been studied under reducing conditions. This compound exhibits a completely disordered distribution of iron and cobalt over the two crystallographically distinct sites in the $14 / \mathrm{mmm}$ structure. Heating this compound under $5 \% \mathrm{H}_{2}$ in $\mathrm{N}_{2}$ reveals the presence of a stable reduced phase in the range $500<T /{ }^{\circ} \mathrm{C}<800$ giving a stoichiometry of $\mathrm{LaSr}_{3} \mathrm{Fe}_{1.5} \mathrm{Co}_{1.5} \mathrm{O}_{8.25}$. However, reaction with $\mathrm{CaH}_{2}$ in a sealed tube affords a more dramatic reduction to yield $\mathrm{LaSr}_{3} \mathrm{Fe}_{1.5} \mathrm{Co}_{1.5} \mathrm{O}_{7.49}$ and hence a mean oxidation state of only +2 for the transition metals. ${ }^{13}$ As in the $\mathrm{YSr}_{2} \mathrm{Mn}_{2} \mathrm{O}_{7-\delta}$ system, the oxide is withdrawn from the centre of the perovskite block and in this case the extreme reduction leads to a remarkable three-coordinate environment for $\mathrm{Fe}^{2+}$ and $\mathrm{Co}^{2+}$ shown in Fig. 2. The exceptionally short Fe/Co-O distances, 1.787(7) $\mathrm{A}$, observed in this material are necessary in order for only three oxide anions to stabilise the cation charge.

Partial reduction of three-dimensional structures have also led to interesting anion vacancy distributions. The high pressure oxidation of the $n=1$ brownmillerite phase $\mathrm{Ca}_{2} \mathrm{MnAlO}_{5}$ oxidises alternate layers of $\mathrm{AlO}_{4}$ tetrahedra to $\mathrm{AlO}_{6}$ octahedra and thus yields the first bulk sample of the $n=3$ brownmillerite structure [Imma; $a=5.2860(1), b=29.5334(6), c=5.4027(1) \AA] .{ }^{14}$ It is argued that the unprecedented preservation of order in the anion sublattice arises from the relatively large strain introduced by $\mathrm{Ca}^{2+}$ providing a large barrier to oxide migration. Reduction of the distorted perovskite $\mathrm{LaMnO}_{3}$ reveals the presence of anion ordering for a material of composition $\mathrm{LaMnO}_{2.75}$ (or $\mathrm{La}_{4} \mathrm{Mn}_{4} \mathrm{O}_{11}$ ). ${ }^{15}$ This material contains all of the oxide vacancies in one of every four layers giving a triple block of octahedrally coordinated $\mathrm{Mn}^{2.67+}$ separated by a layer of $\mathrm{Mn}^{2+}$ in tetrahedral coordination which provides an interesting contrast to other vacancy ordered manganates such as $\mathrm{Sr}_{2} \mathrm{Mn}_{2} \mathrm{O}_{5}$ where $\mathrm{Mn}^{3+}$ is found in square pyramidal coordination. $\mathrm{La}_{4} \mathrm{Mn}_{4} \mathrm{O}_{11}$ shows weak ferromagnetism below a magnetic transition at $50 \mathrm{~K}$. An alternative approach to inducing charge ordering has been reported in the system $\mathrm{Bi}_{1-x} \mathrm{Ca}_{x} \mathrm{MnO}_{3} .{ }^{16}$ The compositions $x=0.45$ and 0.40 have been studied either side of the structural transition at $330 \mathrm{~K}$ using an impressive combination of single crystal diffraction, superspace crystallography and electron microscopy techniques to establish the nature of the structural transition. Above $330 \mathrm{~K}$ a single manganese site is observed and the structure can be described as a $\mathrm{GdFeO}_{3}$-type distortion of the perovskite structure $[P n m a]$ with a regular distribution of oxide anions around the Mn centre. Data collected at $150 \mathrm{~K}\left[\mathrm{Pnm}_{1}\right]$ show the presence of two manganese sites with an pronounced Jahn-Teller distortion indicating the presence of $\mathrm{Mn}^{3+}$ and allow the assignment of orbital ordering as the driving force for this structural transition. 

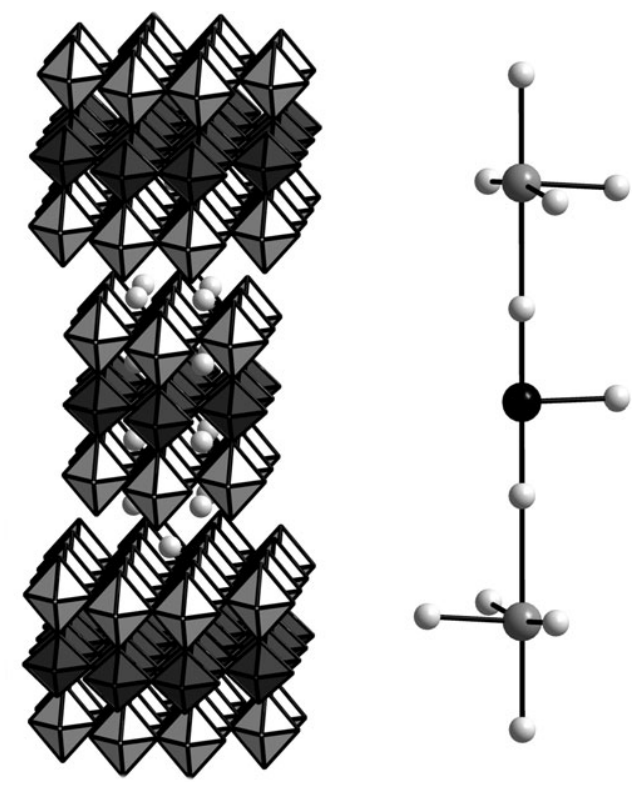

Fig. 2 The $n=3$ Ruddlesden-Popper phase $\mathrm{LaSr}_{3} \mathrm{Fe}_{1.5} \mathrm{Co}_{1.5} \mathrm{O}_{10.1}$ (left) can be reduced to $\mathrm{LaSr}_{3} \mathrm{Fe}_{1.5} \mathrm{Co}_{1.5} \mathrm{O}_{7.49}$ giving three coordination around the central metal in the triple perovskite block. $^{13}$

The system $\mathrm{BaMnO}_{3-\delta}$ shows a wide range of perovskites containing various ratios of face- and corner-sharing octahedral sites. The $4 \mathrm{H}$ phase contains an equal proportion of each type of linkage and a study of the $4 \mathrm{H}$ phases $\mathrm{BaMnO}_{3-\delta}(0 \leq \delta$ $\leq 0.35)$ and $\mathrm{Ba}_{0.5} \mathrm{Sr}_{0.5} \mathrm{MnO}_{3-\delta}(0 \leq \delta \leq 0.21)$ has located the anion vacancies in the shared faces ${ }^{17}$ rather than in the corner linkages as had previously been believed. This has important consequences for the magnetic properties of hexagonal perovskites containing manganese. It is argued that the observed vacancy distribution is a function of the different strengths of the $\mathrm{Mn}-\mathrm{O}$ bonds in the structure. Purely facelinked polyhedra are reported for $L n_{3-x} \mathrm{Na}_{x} \mathrm{Na}_{B} \mathrm{O}_{6}(L n=\mathrm{La}, \mathrm{Pr}, \mathrm{Nd} ; B=\mathrm{Rh}, \mathrm{Pt})$ giving one-dimensional crystal structures. ${ }^{18}$ In these compounds the chains are composed of an alternating arrangement of trigonal prisms and octahedra occupied by $\mathrm{Na}^{+}$and $\mathrm{Rh}^{2+2 x}$, respectively. One dimensional connectivity also exists in the complex structure of $\mathrm{Na}_{2} \mathrm{Te}_{3} \mathrm{Mo}_{3} \mathrm{O}_{16}{ }^{19}$ This compound contains trimers of $\mathrm{MoO}_{6}$ octahedra linked to form chains by corner linking with $\mathrm{TeO}_{3}$ and $\mathrm{TeO}_{4}$ polyhedra. All three of the metal oxide polyhedra show large polarisations with Mo-O distances varying from $1.727(7)$ to $2.213(7) \AA$ within the octahedra. The non-centrosymmetric space group $\left[I 2 ; a=7.3373(10), b=11.2668(16), c=8.2369(18) \AA, \beta=97.387(3)^{\circ}\right]$ propagates these displacements through the structure leading to a net polarisation and second harmonic generation 500 times greater than that of $\alpha-\mathrm{SiO}_{2}$.

The $\mathrm{Mn}^{4+}$ compound $\mathrm{Ba}_{4} \mathrm{YMn}_{3} \mathrm{O}_{11.5}$ contains a mixture of cubic and hexagonal stacking of $\mathrm{BaO}_{3}$ layers leading to the formation of face-sharing $\mathrm{Mn}_{3} \mathrm{O}_{12}$ trimers separated by $\mathrm{YO}_{6}$ octahedra in a rhombohedral structure containing 12 layers in the repeat unit $[R \overline{3} m ; a=5.78752(3), c=28.6213(3) \AA] .{ }^{20}$ The anion vacancies are found exclusively in the layer that links the trimers to the $\mathrm{YO}_{6}$ units leading to $40 \%$ of yttrium being in an unusual five coordination environment. This material shows 
an internal barrier layer capacitance between resistive grains and even more resistive grain boundary regions.

The perovskite phase of $\mathrm{YbMnO}_{3}$ can be stabilised by annealing the common layered polymorph of this material at $5 \mathrm{GPa}$ and $1100{ }^{\circ} \mathrm{C}$. Characterisation of this material at ambient pressure reveals that due to the small size of the $\mathrm{Yb}^{3+}$ cation this perovskite is exceptionally distorted with an average $\mathrm{Mn}-\mathrm{O}-\mathrm{Mn}$ angle of only $141.9^{\circ} .^{21}$ The $\mathrm{Mn}^{3+}$ moments order antiferromagnetically at $43 \mathrm{~K}$ with $\mathrm{Yb}^{3+}$ moments ordering in a separate transition around $4 \mathrm{~K}$. The spinel phase $\mathrm{LiMn}_{2} \mathrm{O}_{4}$ has been widely studied as a potential intercalation electrode for operation in secondary lithium batteries. The chemistry of this system has been extended by the report of a high pressure polymorph which adopts the $\mathrm{CaFe}_{2} \mathrm{O}_{4}$ structure. ${ }^{22}$ This transformation is favoured by the $6 \%$ reduction in volume associated with the adoption of the $\mathrm{CaFe}_{2} \mathrm{O}_{4}$ structure containing a mixture of edge- and corner-linked $\mathrm{MnO}_{6}$ octahedra and lithium in unusual 8-coordination. The structural transformation is associated with the formation of a lithium-rich impurity and so the stoichiometry of the high pressure phase is estimated to be close to $\mathrm{Li}_{0.92} \mathrm{Mn}_{2} \mathrm{O}_{4}$. Measurements of magnetisation and specific heat suggest an electronic transition at $10 \mathrm{~K}$ to a spin glass phase.

A novel cuprate has been synthesised at elevated pressure and found to be metastable at ambient temperature and pressure. $\mathrm{Eu}_{2} \mathrm{CaCu}_{2} \mathrm{O}_{6}$ contains a new type of copper oxygen plane, $\mathrm{CuO}_{3}$, composed of edge sharing between pairs of $\mathrm{CuO}_{4}$ squares to give isolated $\mathrm{Cu}_{2} \mathrm{O}_{6}$ units. ${ }^{23}$ The structure is built up by alternation of these layers with $\mathrm{Eu}_{2} \mathrm{Ca}$ planes that contain a fully ordered arrangement of $\mathrm{Ca}^{2+}$ and $\mathrm{Eu}^{3+}$ over crystallographically distinct square antiprismatic coordination sites. The magnetic properties of this compound are dominated by the strong interactions between $\mathrm{Eu}^{3+}$. However, the strong antiferromagnetic coupling in this material does not lead to spin freezing above $6 \mathrm{~K}$, suggesting the presence of considerable magnetic frustration.

A number of potentially useful ferroelectric materials have been synthesised using elevated pressure. $\mathrm{BiAlO}_{3}$ prepared under $6 \mathrm{GPa}$ and $1000{ }^{\circ} \mathrm{C}$ forms a noncentrosymmetric perovskite that survives quenching to room temperature and pressure. ${ }^{24}$ The second harmonic generation effect observed for this compound supports the assignment of the non-centrosymmetric space group $R 3 c$ that was made on the basis of powder diffraction data. The displacement of $\mathrm{Al}^{3+}$ and $\mathrm{O}^{2-}$ from the positions in the centrosymmetric structure leads to a calculated polarisation of $32 \mu \mathrm{C}$ $\mathrm{cm}^{-2}$. By contrast, the structure of $\mathrm{BiGaO}_{3}$ under similar conditions contains chains of $\mathrm{GaO}_{4}$ tetrahedra separated by six coordinate $\mathrm{Bi}^{3+}$ in a centrosymmetric arrangement $[$ Pcca; $a=5.4162(2), b=5.1335(3), c=9.9369(5) \AA] .{ }^{24}$ Similar reaction conditions have been used to stabilise the perovskite phase $\mathrm{Bi}_{2} \mathrm{ZnTiO}_{6}{ }^{25}$ This exhibits the same structural distortion as the ferroelectric material $\mathrm{PbTiO}_{3}$ although the metric tetragonal distortion in $\mathrm{Bi}_{2} \mathrm{ZnTiO}_{6}$ is considerably larger with a $c / a$ ratio of 1.211 at room temperature. The displacement of the $\mathrm{Zn} / \mathrm{Ti}$ cations from the centre of the octahedra is so large that they are considered to reside in square-based pyramidal coordination and this leads to an exceptionally large static polarisation which is more than double that observed in $\mathrm{PbTiO}_{3}$.

The $\mathrm{Bi}_{2} \mathrm{O}_{3}$ system continues to be a source of fascinating chemistry. A hydrothermal route to this compound has yielded a new polymorph, $\varepsilon-\mathrm{Bi}_{2} \mathrm{O}_{3}{ }^{26}$ The structure of this phase can be considered to be built up from edge sharing $\mathrm{OBi}_{4}$ tetrahedra with the two additional oxide anions on each $\mathrm{Bi}^{3+}$ occupying terminal positions. The resultant chains of $\mathrm{Bi}_{2} \mathrm{O}_{3}$ are a feature common to the $\alpha$ and $\beta$ 
polymorphs and the $\varepsilon$ phase transforms to the $\alpha-\mathrm{Bi}_{2} \mathrm{O}_{3}$ on heating to $400{ }^{\circ} \mathrm{C}$. The highly ordered structure of $\varepsilon-\mathrm{Bi}_{2} \mathrm{O}_{3}$ leads to negligible ionic mobility. By contrast the oxide ion conductivity of $\delta$ - $\mathrm{Bi}_{2} \mathrm{O}_{3}$ can be enhanced by stabilising this structure by addition of low concentrations of lanthanides and $\mathrm{Re}^{\mathrm{VII}}$ to give phases $\mathrm{Bi}_{12.5} L n_{1.5^{-}}$ $\mathrm{ReO}_{24.5}{ }^{27}$ The structure is described in the space group $F m \overline{3} m(a=5.6000$ (7) $\AA$ for $L n=\mathrm{Nd}$ ) although the large displacement parameters observed for both cations and anions indicates the presence of considerable local disorder and strain in the lattice. The interstitial oxide anion in these compounds is displaced from the position occupied in related phases stabilised by doping with smaller lanthanides and this may be the origin of the exceptional ion mobility; these phases are the best low temperature isotropic oxide ion conductors yet reported.

\section{Oxyanions}

The utilisation of various oxyanions to produce continuous, often highly complex, structures has continued apace. The study of condensed borates is strongly motivated by the non-linear optical behaviour of $\alpha-\mathrm{BiB}_{3} \mathrm{O}_{6}$. The $\beta$ and $\gamma$ polymorphs both crystallise in the centrosymmetric space group $P 2_{1} / n$ and so are unable to reproduce the useful behaviour of $\alpha-\mathrm{BiB}_{3} \mathrm{O}_{6}$. The application of a high pressure synthetic route in this system has led to the identification and structural characterisation of a new non-centrosymmetric modification of this structure, $\delta$ - $\mathrm{BiB}_{3} \mathrm{O}_{6} \cdot{ }^{28}$ Heating stoichiometric quantities of the component oxides under $5.5 \mathrm{GPa}$ and $820{ }^{\circ} \mathrm{C}$ gave a single crystal that was stable under ambient conditions. The structure could be modelled in the space group $P c a 2_{1}$ and contains layers of corner sharing $\mathrm{BO}_{4}$ units that are themselves linked by chains of $\mathrm{BO}_{4}$ to give a three dimensional connectivity that is similar to that of $\gamma-L n \mathrm{~B}_{3} \mathrm{O}_{6}$. The crucial difference in $\delta-\mathrm{BiB}_{3} \mathrm{O}_{6}$ arises from the reduction in coordination number for the metal from e.g. ten in $\mathrm{CeB}_{3} \mathrm{O}_{6}$ to seven in $\delta$ - $\mathrm{BiB}_{3} \mathrm{O}_{6}$ due to the sterically active lone pair of $\mathrm{Bi}^{3+}$. This structural distortion is responsible for the non-centrosymmetric structure and leads to a considerable second harmonic generation effect. Ab initio structure solution from neutron powder diffraction data has identified the structures of two new noncentrosymmetric borate oxides $M \mathrm{Bi}_{2} \mathrm{~B}_{2} \mathrm{O}_{7}(M=\mathrm{Ca}, \mathrm{Sr}){ }^{29}$ Both compounds are composed of layers of $\mathrm{BO}_{3}$ triangles linked by shared corners, with the interlayer regions containing alkaline earth cations residing in trigonal prisms composed of oxide anions and $\mathrm{Bi}_{2} \mathrm{O}$ groups. The calcium compound exhibits lower symmetry $\left[\right.$ Pna $_{1} ; a=8.9371(5), b=$ 5.4771(3), $c=12.5912(7) \AA]$ than the strontium analogue $\left[P 6_{3} ; a=9.1404(4)\right.$, $c=13.0808(6) \AA]$ due to the crystallisation of disorder which is manifested on a local scale in $\mathrm{SrBi}_{2} \mathrm{~B}_{2} \mathrm{O}_{7}$ by large displacement parameters. The $\mathrm{Bi}^{3+}$ cations are displaced from the centre of the six-coordinate site and $\mathrm{CaBi}_{2} \mathrm{~B}_{2} \mathrm{O}_{7}$ shows modest second harmonic generation.

Incorporation of $\mathrm{Pb}^{2+}$ and $\mathrm{Bi}^{3+}$ into a borate could be anticipated to lead to strong second harmonic generation but the new structure formed by $\mathrm{PbBiBO}_{7}$ is centrosymmetric $\left[P 2_{1} / n ; a=7.473(1), b=7.517(1), c=7.609(1) \AA, \beta=\right.$ $\left.91.48(1)^{\circ}\right] .^{30} \mathrm{~Pb}^{2+}$ and $\mathrm{Bi}^{3+}$ are both located in heavily distorted six-coordinate environments which show considerable local polarisation but antiparallel orientation of neighbouring dipoles leads to complete cancellation. A similar approach has led to the first example of a borate containing $\mathrm{Se}^{\mathrm{IV}} ; \mathrm{Se}_{2} \mathrm{~B}_{2} \mathrm{O}_{7}{ }^{31}$ This compound contains a three dimensional structure composed of $\mathrm{B}_{2} \mathrm{O}_{7}{ }^{8-}$ anions and selenium in trigonal pyramidal sites with the stereoactive lone pair occupying the fourth ligand position. The polarisation associated with these $\mathrm{SeO}_{3}$ units is propagated through 
the structure $\left[P 2_{1} 2_{1} 2_{1}\right]$ and results in efficient second harmonic generation. Moreover this material is transparent across the range $400-2000 \mathrm{~nm}$ and so may find application in the UV, visible and near IR region of the spectrum as a non-linear optical material. Similar structural considerations lead to the presence of highly distorted $\mathrm{Te}^{\mathrm{IV}}$ environment in $\mathrm{Ba}_{2} \mathrm{TeO}\left(\mathrm{PO}_{4}\right)_{2} \cdot{ }^{32}$ This material contains a onedimensional structure composed of $\mathrm{PO}_{4}$ tetrahedra and $\mathrm{TeO}_{5}$ polyhedra although the dipole associated with the latter are cancelled by an inversion centre $[P \overline{1}]$. Interestingly, dipole calculations show that the more directional lone pair of $\mathrm{Te}^{\mathrm{IV}}$ leads to a larger dipole moment that $\mathrm{Bi}^{3+}$ analogues.

$\mathrm{ZrP}_{2} \mathrm{O}_{7}$ has been widely studied due to the observed isotropic negative thermal expansion above $566 \mathrm{~K}$. The room temperature structure of this compound has been problematic, but was solved in 2006 independently by two groups that approached the problem in different ways. A low temperature, hydrothermal preparation of this compound yielded untwinned microcrystals suitable for analysis at a synchrotron source. ${ }^{33}$ Simultaneously the space group [Pbca; $a=24.7437, b=24.7258, c=$ $24.7407 \AA$ ] and structure were identified by a tour de force of structure solution from a combination of neutron powder diffraction and solid state NMR. ${ }^{34}$ The structure contains 136 crystallographically unique atoms with additional complexity arising from the apparently higher metric symmetry of the unit cell. The structure contains relatively regular $\mathrm{ZrO}_{6}$ and $\mathrm{PO}_{4}$ units in a rock salt arrangement, as observed in the high temperature structure, with subtle variation in the angles between these units.

A new phase $\mathrm{LiGd}\left(\mathrm{PO}_{3}\right)_{4}$ contains chains of corner sharing phosphate linked by $\mathrm{GdO}_{8}$ and $\mathrm{LiO}_{4}$ units and modest ionic conductivity. ${ }^{35}$ Ion mobility has been utilised to synthesise $\mathrm{Fe}_{0.5} \mathrm{TiO}\left(\mathrm{PO}_{4}\right)$ by reaction of metallic iron with $\mathrm{Cu}_{0.5} \mathrm{TiO}\left(\mathrm{PO}_{4}\right)$ to give a three-dimensional structure composed of $\mathrm{TiO}_{6}$ and $\mathrm{FeO}_{6}$ octahedra linked by shared faces linked to phosphate groups by shared apices. ${ }^{36} \mathrm{The}^{\mathrm{Ti}^{4+}}$ cations are significantly displaced from the centre of the octahedra but the centrosymmetric space group $P 2_{1} / c$ precludes interesting optical properties.

Oxide anion mobility has been observed in $\mathrm{Ca}_{3}\left(\mathrm{SiO}_{4}\right) \mathrm{O}$ and $\mathrm{Ca}_{2.93} \mathrm{Mg}_{0.07}\left(\mathrm{Si}_{0.98^{-}}\right.$ $\left.\mathrm{Al}_{0.02} \mathrm{O}_{4}\right) \mathrm{O}_{0.99}$ (vacancy) $)_{0.01}{ }^{37}$ The subtle doping in the latter compound avoids the complications of high-temperature structural transitions manifested in undoped $\mathrm{Ca}_{3}\left(\mathrm{SiO}_{4}\right) \mathrm{O}$ and allows the identification of complex conductivity involving oxide, proton and n-type conduction under various atmospheres. A family of uranium phosphate fluorides $A\left(\mathrm{UO}_{2}\right) \mathrm{F}\left(\mathrm{HPO}_{4}\right) \cdot x \mathrm{H}_{2} \mathrm{O}(A=\mathrm{Cs}, \mathrm{Rb}, \mathrm{K})$ adopt a range of layered structures containing $\mathrm{UO}_{5} \mathrm{~F}_{2}$ pentagonal bipyramids. The alkali metals reside in the interlayer space and are readily exchangeable in all three compounds. ${ }^{38}$ Alkali metal mobility has also been reported in the three dimensional borophosphates $\mathrm{Na}_{5}\left(\mathrm{H}_{3} \mathrm{O}\right)\left\{\mathrm{M}_{3}^{\mathrm{II}}\left[\mathrm{B}_{3} \mathrm{O}_{3}(\mathrm{OH})\right]_{3}\left(\mathrm{PO}_{4}\right)_{6}\right\} \cdot 2 \mathrm{H}_{2} \mathrm{O}\left(\mathrm{M}^{\mathrm{II}}=\mathrm{Mn}, \mathrm{Co}, \mathrm{Ni}\right) .{ }^{39}$ These isostructural compounds contain $\left[\mathrm{M}\left(\mathrm{PO}_{4}\right)_{2}\right]^{4-}$ layers connected by $\mathrm{B}_{3} \mathrm{O}_{7} \mathrm{OH}$ units. $\mathrm{Na}^{+}$is distributed over sites within the walls of the 12-ring and 6-ring channels in the structure and shows thermally-activated mobility which is comparable to related phosphates but considerably lower than fast $\mathrm{Na}^{+}$conductors such as $\beta$-alumina. The metal phosphate layers distribute the paramagnetic cations over the points of a Kagomé lattice at a separation of $\approx 6 \AA$. These compounds are paramagnetic from $4 \mathrm{~K}$ to room temperature although the absence of a magnetic transition may be due to the extremely weak nature of the antiferromagnetic coupling in these compounds rather than arising from geometric frustration.

Sodium mobility through a tunnel structure is also observed in $\mathrm{Na}_{2} \mathrm{Co}_{8}\left(\mathrm{PO}_{4}\right)_{6}{ }^{40}$ This compound contains a three-dimensional framework composed of $\mathrm{CoO}_{5}$ pyramids and $\mathrm{PO}_{4}$ tetrahedra linked by a mixture of corner- and edge-sharing. This 
gives rise to irregular hexagonal channels running through the structure which accommodate $\mathrm{Na}^{+}$in a slightly larger site than in other cobalt phosphates. The presence of site vacancies on these sites are believed to ease $\mathrm{Na}^{+}$hopping along the channels resulting in ionic conductivity above $600 \mathrm{~K}$. Similarly, $\mathrm{Cs}_{2} \mathrm{Cu}_{3} \mathrm{P}_{4} \mathrm{O}_{14}$ contains a framework composed of square planar $\mathrm{CuO}_{4}$ linked via corner sharing by $\mathrm{P}_{2} \mathrm{O}_{7}$ units with $\mathrm{Cs}^{+}$found in an 8-coordinate site in the pseudo-one-dimensional channels. ${ }^{41}$ The $\mathrm{CuO}_{4}$ units are linked via two bridging phosphate groups to form linear trimeric clusters of $\mathrm{CuO}_{4}$ with an intermetallic distance of 2.71(1) $\AA$. At high temperature this material is a paramagnet which exhibits modest antiferromagnetic coupling. However, on cooling the material there is a weak ferromagnetic transition at $14 \mathrm{~K}$.

An unusual layered structure has been identified in a new aluminophosphate, SIZ-6, synthesized by using an ionic liquid as both reaction medium and structure directing agent in a hydrothermal reaction. ${ }^{42}$ The aluminium shows a mixture of largely regular tetrahedral and octahedral coordination environments and an additional site which is mostly five-coordinate but is associated with a site that is partially occupied by oxygen that results in this aluminium being six-coordinate in $20 \%$ of these sites. This introduces considerable disorder into the coordination sphere of the adjacent phosphorus atom. The resultant layers are $13.5 \AA$ thick and contain rings formed from 4,6 and 8 nodes that suggest that this material may demonstrate porosity to small molecules. The layers carry a single negative charge that is balanced by one 1-ethyl-3-methylimidazolium cation in the interlayer space and are held together by relatively strong hydrogen bonding between $\mathrm{H}_{2} \mathrm{PO}_{4}$ groups in adjacent layers.

A zinc phosphite, $\left.\left[\mathrm{C}_{4} \mathrm{H}_{12} \mathrm{~N}\right)_{2}\right]\left[\mathrm{Zn}_{3}\left(\mathrm{HPO}_{3}\right)_{4}\right]$ has been reported which contains channels which are considerably larger than any voids previously observed in any metal phosphite. ${ }^{43}$ This charged framework is composed of $\mathrm{ZnO}_{4}$ tetrahedra and $\mathrm{HPO}_{3}$ pseudo-pyramids in a strictly alternating arrangement. The structure contains 24- and 8-ring channels and the dimensions of the former, $11.0 \times 11.0 \AA^{2}$, are considerably larger than the 16-ring channels previously identified as the largest channels in metal phosphites. The framework charge is balanced by eight $\mathrm{CH}_{3}\left(\mathrm{CH}_{2}\right)_{3} \mathrm{NH}_{3}{ }^{+}$cations that are located in each 24-ring window. The smaller 8-ring channels are unoccupied and the dimensions of these voids, $3.4 \times 3.4 \AA^{2}$, suggest that these may provide useful porosity. The framework collapses with the thermal decomposition of the $n$-butlylammonium cations that occurs on heating the material above $160{ }^{\circ} \mathrm{C}$.

The silicogermanate zeolite ITQ-33 contains 18-ring channels that intersect with 10 -ring channels to produce a structure with extremely large micropore volume. ${ }^{44}$ This hexagonal structure $[P 6 / \mathrm{mmm} ; a=19.367, c=11.495 \AA]$ was prepared under hydrothermal conditions and employed hexamethonium as a structure-directing agent to yield a material of composition |(hexamethonium $)_{0.07} \mathrm{~F}_{0.07}\left(\mathrm{H}_{2} \mathrm{O}\right)_{0.37} \mid$ $\left[\mathrm{Si}_{0.66} \mathrm{Al}_{0.04} \mathrm{Ge}_{0.30} \mathrm{O}_{2.02}\right]$. The structure survives removal of the guests by calcination at $550{ }^{\circ} \mathrm{C}$ yielding a material with a framework density of 12.3 tetrahedral atoms per $1000 \AA$ and a surface area, measured by BET analysis, of $690 \mathrm{~m}^{2} \mathrm{~g}^{-1}$ and a micropore volume of $0.30 \mathrm{~cm}^{3} \mathrm{~g}^{-1}$. The surface acidity of ITQ-33 is effective at catalysing the alkylation of benzene with propylene to produce cumene with better long-term stability than Beta zeolite that is currently used commercially for this process. ITQ-33 is also a highly effective cracking catalyst producing more diesel and less gasoline than USY, presumably as a result of the larger connecting pores allowing diffusion of gasoline molecules. 
Hydrothermal reaction has afforded crystals of the chiral silicate $\mathrm{Na}_{3} \mathrm{~Tb}$ $\mathrm{Si}_{3} \mathrm{O}_{9} \cdot 3 \mathrm{H}_{2} \mathrm{O}\left[P 2_{1} 2_{1} 2_{1} ; a=7.0280(14), b=11.757(2), c=13.503(3) \AA\right]$. The chirality is imparted to the structure by a remarkable $\Lambda$-Co(en $)_{3}{ }^{2+}$-like unit of $\mathrm{TbSi}_{6} \mathrm{O}_{9}$ as shown in Fig. $3{ }^{45}$ The negative charge of the $\left[\mathrm{TbSi}_{3} \mathrm{O}_{9}\right]^{3-}$ is balanced by $\mathrm{Na}^{+}$occupying the 9-ring channels that run through the structure with an aperture of $3.1 \times 7.0 \AA$ and it is anticipated that ion-exchange may provide a route to new structurally-related compounds. The incorporation of lanthanum into bismuth silicate has stabilised a tetragonal structure in the system $\mathrm{Bi}_{2-x} \mathrm{La}_{x} \mathrm{SiO}_{5}(x \approx$ $0.1){ }^{46}$ This structure is composed of alternating layers of $\left[(\mathrm{Bi} / \mathrm{La})_{2} \mathrm{O}_{2}\right]^{2+}$ and $\left[\mathrm{SiO}_{3}\right]^{2-}$ and can be considered to be related to the $n=1$ Aurivillius structure by replacement of the perovskite slab with a sheet of corner-sharing tetrahedral $\mathrm{SiO}_{4}$ units. The cation occupational disorder in this compound introduces positional disorder in the oxide sublattice and distortion in the silicon environment that means that these units can be considered to consist of anion deficient octahedra, $\left[\mathrm{SiO}_{4}\right.$ (vacancy $)_{2}$ ]. It is argued that the positional disorder in the stereoactive lone pair associated with $\mathrm{Bi}^{3+}$ in this compound causes the higher symmetry $[14 / \mathrm{mmm} ; a=$ 3.8307(1), $c=15.227(1) \AA$ ] compared to the orthorhombic phase $\mathrm{Bi}_{2} \mathrm{SiO}_{5}$ in which the effect of the lone pair is crystallographically propagated through the structure.

Synchrotron X-ray powder diffraction data have been combined with high quality high-resolution transmission electron microscopy images to solve the extremely complex structure of the highly silaceous zeolite TNU-9 $\left(\left|\mathrm{H}_{9.3}\right|\left[\mathrm{Al}_{9.3} \mathrm{Si}_{182.7} \mathrm{O}_{384}\right]\right)$ which contains 24 topologically and crystallographically distinct $\mathrm{Si} / \mathrm{Al}$ atoms [C2/m; $\left.a=28.2219, b=20.0123, c=19.4926 \AA, \beta=92.33^{\circ}\right]$ and is the most complex zeolite structure yet known. ${ }^{47}$ This material contains a three-dimensional 10-ring channel system that is similar to the structure of ZSM-5. An alternative solution to the challenge of structure solution from powder diffraction data is demonstrated by the approach shown in determining the structure of $\mathrm{Na}_{2}\left[(\mathrm{VO})_{2}\left(\mathrm{HPO}_{4}\right)_{2}\right.$ $\left.\mathrm{C}_{2} \mathrm{O}_{4}\right] \cdot 2 \mathrm{H}_{2} \mathrm{O}$. ${ }^{48}$ This forms a vanadium phosphate framework by linking vanadium oxide octahedra and hydrogenphosphate tetrahedra together via shared vertices to give infinite chains. These chains are linked together by bridging oxalate anions to give a two-dimensional structure with water and $\mathrm{Na}^{+}$located between the resultant layers. The low symmetry of the structure $\left[P 2_{1} ; a=6.3534(1), b=17.1614(3), c=\right.$ $6.5632(1) \AA]$ was identified using a direct methods analysis of X-ray powder diffraction data to generate a plausible structural model and then using additional
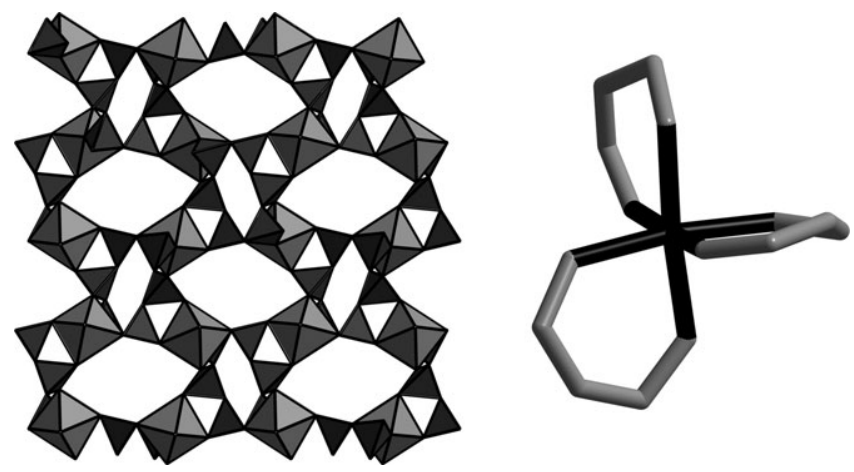

Fig. 3 The framework of $\mathrm{Na}_{3} \mathrm{TbSi}_{3} \mathrm{O}_{9}$ is composed of $\mathrm{TbO}_{6}$ octahedra and $\mathrm{SiO}_{4}$ tetrahedra represented by light and dark polyhedra, respectively. The $\left[\mathrm{TbSi}_{6} \mathrm{O}_{9}\right]$ unit forms a chiral $\Lambda$-Co(en) $3^{3+}$ unit. $^{45}$ 
information on the number of symmetry-inequivalent sodium positions obtained from NMR to distinguish the correct space group from alternative models. The availability of NMR data was vital in excluding the plausible alternative space group $P 2_{1} / m$. The presence of paramagnetic species in the material and the fact that decomposition occurred under the conditions of magic angle spinning make it particularly impressive that this crucial information could be extracted from the spectra.

A two-dimensional structure is also observed in the vanadate $\mathrm{Ba}_{2.5}\left(\mathrm{VO}_{2}\right)_{3^{-}}$ $\left(\mathrm{SeO}_{3}\right)_{4} \cdot \mathrm{H}_{2} \mathrm{O}$ with layers composed of $\mathrm{VO}_{5}$ square pyramids and $\mathrm{SeO}_{3}$ trigonal pyramids. ${ }^{49}$ The vanadium environment shows considerable variation in $\mathrm{V}-\mathrm{O}$ distances attributed to the presence of $\mathrm{V}=\mathrm{O}$ bonding. Bond valence sums indicate that the cation environments are plausible for $\mathrm{V}^{5+}$ and $\mathrm{Se}^{4+}$. Despite the presence of both polyhedral distortion and the stereoactive lone pair this material has no role as a second harmonic generation due to the adoption of a centrosymmetric space group $[P \overline{3}]$. The related composition $\mathrm{La}\left(\mathrm{VO}_{2}\right)_{3}\left(\mathrm{TeO}_{6}\right) \cdot 3 \mathrm{H}_{2} \mathrm{O}$ shows a three dimensional structure containing $\mathrm{VO}_{4}$ tetrahedra and $\mathrm{TeO}_{6}$ octahedra. ${ }^{49}$ The octahedra are largely regular and share all six vertices with $\mathrm{VO}_{4}$ tetrahedra which act as linear bridging connectors between the octahedral units. Despite the noncentrosymmetric symmetry of this compound $[R 3 c]$ this material shows negligible second harmonic generation.

The layered cobalt hydroxysulfate $\mathrm{Co}_{5}(\mathrm{OH})_{6}\left(\mathrm{SO}_{4}\right)_{2}\left(\mathrm{H}_{2} \mathrm{O}\right)_{4}$ contains divalent octahedrally-coordinated cobalt in brucite layers. ${ }^{50}$ These are linked by an unusual pillaring arrangement of $\mathrm{O}_{3} \mathrm{SO}-\mathrm{Co}\left(\mathrm{H}_{2} \mathrm{O}\right)_{4}-\mathrm{OSO}_{3}$, i.e. the pillars contain paramagnetic species. This material orders ferromagnetically below $T_{\mathrm{C}}=14 \mathrm{~K}$ and this temperature can be increased at a rate of $0.12 \mathrm{~K} \mathrm{kbar}^{-1}$ by the application of pressure. The magnetic structure shows alignment of the Co moments within the layer along the $b$-direction whilst the magnetic moment of the pillars remain randomised. The resultant magnetic ordering is purely two-dimensional and this material is classed as a single layer magnet.

The compounds $A_{8}\left[\left(\mathrm{UO}_{2}\right)_{4}\left(\mathrm{WO}_{4}\right)_{4}\left(\mathrm{WO}_{5}\right)_{2}\right](A=\mathrm{Rb}, \mathrm{Cs})$ are isostructural and contain chains of composition $\left.\left[\mathrm{UO}_{2}\right)_{4}\left(\mathrm{WO}_{4}\right)_{4}\left(\mathrm{WO}_{5}\right)_{2}\right]^{4-}$ consisting of $\mathrm{WU}_{4} \mathrm{O}_{25}$ pentamers that are linked by $\mathrm{WO}_{5}$ and $\mathrm{WO}_{4}$ units of square pyramidal and tetrahedral geometry, respectively. A mixture of tungsten coordination environments are also present in the related compound $\mathrm{Rb}_{6}\left[\left(\mathrm{UO}_{2}\right)_{2} \mathrm{O}\left(\mathrm{WO}_{4}\right)_{4}\right]^{51}$ The uranium oxide fluoride $\left[\mathrm{N}\left(\mathrm{CH}_{3}\right)_{4}\right]\left[\left(\mathrm{UO}_{2}\right)_{2} \mathrm{~F}_{5}\right]$ contains a three-dimensional open framework built from $\mathrm{UO}_{2} \mathrm{~F}_{5}$ units. ${ }^{52}$ These pentagonal bipyramidal units are linked by edge-sharing to produce infinite chains running along the [010] and [100] directions of the unit cell. Interconnectivity in the [001] direction is provided by bridging $\mathrm{UO}_{2} \mathrm{~F}_{5}$ units. This results in ten-membered ring channels of dimensions $2.4 \times 8.8 \AA^{2}$ which compose $45 \%$ of the volume but are partially occupied by the templating tetramethyl ammonium cation. Attempted ion exchange reactions showed that these cations remain immovable and it is argued that the small window size of the channels results in these cations being sealed inside the voids in the structure.

\section{Intermetallics}

A number of beautiful structures and intriguing physical properties have been reported for intermetallic compounds. The first ternary $\mathrm{Li}-\mathrm{Na}-\mathrm{Ba}$ compound has been reported and contains remarkable $\mathrm{Li}_{26}$ clusters. ${ }^{53}$ The absence of miscibility in 
the $\mathrm{Li}-\mathrm{Na}$ system and the large structural differences observed in the $\mathrm{Na}-\mathrm{Ba}$ and $\mathrm{Li}-\mathrm{Ba}$ systems make this observation of $\mathrm{Li}_{13} \mathrm{Na}_{29} \mathrm{Ba}_{19}$ unexpected. The stabilisation of this stoichiometry in a single phase is achieved by the formation of $\mathrm{Li}_{26}$ clusters from interpenetrating icosahedra. This cluster type has been predicted from gasphase calculations but this is the first report of a solid containing such a homoatomic cluster. The cubic structure is built up from a face-centred array of $\mathrm{Li}_{26}$ units with all of the octahedral and half of the tetrahedral interstitial sites filled with $\mathrm{BaBa}_{4} \mathrm{Na}_{12}$ units. The excess $\mathrm{Ba}$ and $\mathrm{Na}$ atoms fill remaining voids in the structure.

An unusual alkali metal environment, for an intermetallic phase, has also been reported in the 1-dimensional structures of $A \mathrm{Au}_{4} \mathrm{In}_{2}(A=\mathrm{K}, \mathrm{Rb}){ }^{54}$ These isostructural compounds contain both 8 -member and 4-member tunnels along the $c$ direction of the unit cell $[I 4 \mathrm{mcm}]$ composed of an $\mathrm{Au}-\mathrm{In}$ framework as shown in Fig. 4. The octagonal channels are occupied by the alkali metals and consequently this structure is highly reminiscent of zeolite chemistry. Most remarkably, this material is stable at room temperature to both air and moisture even in concentrated hydrochloric acid. The mixed compounds $\mathrm{K}_{x} \mathrm{Rb}_{1-x} \mathrm{Au}_{4} \mathrm{In}_{2}$ have been prepared and show increasing disorder in the alkali metal with increasing $\mathrm{Rb}^{+}$content. However, the limited impact of these substitutions on the structure of the tunnel wall suggest very weak interactions between the alkali metal and the framework structure and this is supported by linear muffin-tin-orbital calculations. Combined with the chemical stability of these compounds, this finding suggests that a wide range of experiments analogous to those commonplace in zeolite chemistry may be feasible.

Substitution of magnesium, gold or zinc for indium in a hypothetical $K_{23} \operatorname{In}_{105}$ lattice has afforded three new ternary compounds. ${ }^{55}$ These all consist of complex networks of $\mathrm{In}_{12}$ icosahedra and triply fused $\mathrm{In}(\mathrm{Mg}, \mathrm{Au}, \mathrm{Zn})_{28}$ icosahedra. This anionic framework is bridged by $\mathrm{K}$ atoms to give a clathrate type II network. In each case a line phase is observed and it is argued that the bonding within the cluster containing the doping metal is optimised at the observed compositions.

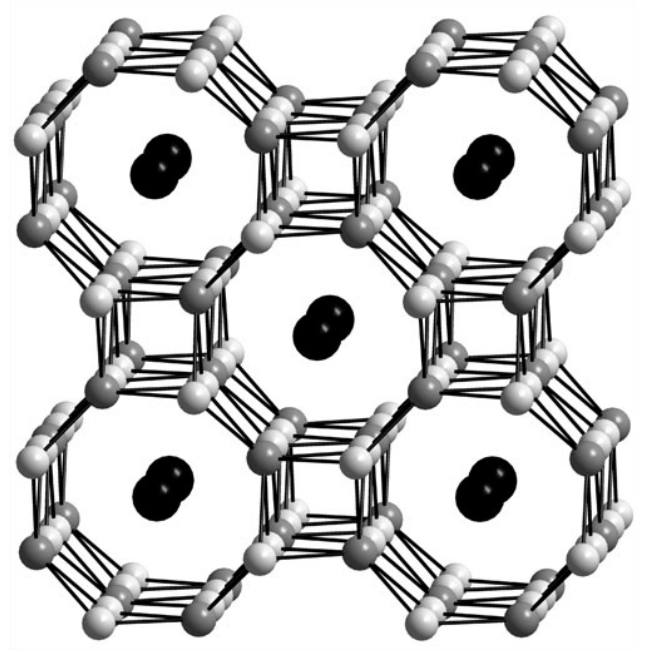

Fig. $4 \mathrm{KAu}_{4} \mathrm{In}_{2}$ and $\mathrm{RbAu} \mathrm{In}_{2}$ contain a network of $\mathrm{Au}$ and In represented by light and dark grey spheres, respectively. The alkali metal resides in the 8 -member tunnel. ${ }^{54}$ 
A clathrate type I structure has been reported for $\mathrm{Ba}_{8} \mathrm{Al}_{13} \mathrm{Si}_{31}{ }^{56}$ This compound contains a covalently bonded framework of aluminium and silicon which accommodates barium in the voids as shown in Fig. 5. Aluminium and silicon are observed on all three crystallographic sites, although the careful application of neutron diffraction and NMR shows that there is a site preference leading to majority aluminium occupation of one of the sites. $\mathrm{Ba}_{8} \mathrm{Al}_{14} \mathrm{Si}_{31}$ shows metallic conductivity and a Seebeck coefficient of $-49 \mu \mathrm{V} \mathrm{K}^{-1}$ at room temperature. The series of doped compounds $\mathrm{Ba}_{8} \mathrm{Cu}_{6-x} \mathrm{Ge}_{40+x}(0 \leq x \leq 0.7)$ have been prepared in the search for a material with enhanced thermoelectric properties. ${ }^{57}$ The reaction of stoichiometric amounts of $\mathrm{Ba}_{6} \mathrm{Ge}_{25}$ and copper provided an excellent degree of control over the $\mathrm{Cu}$ :Ge ratio of the resultant compounds which adopt the type I clathrate structure discussed above. In the case of $\mathrm{Ba}_{8} \mathrm{Cu}_{6} \mathrm{Ge}_{40}$ the copper atoms reside exclusively on the sites favoured by aluminium in $\mathrm{Ba}_{8} \mathrm{Al}_{13} \mathrm{Si}_{31}$. These compounds are semiconducting for small values of $x$ but become increasingly metallic with reducing $\mathrm{Cu}$ concentration and surprisingly show only a small variation in carrier concentration and mobility in response to varying composition. It is argued that this arises from the presence of vacancies on the $\mathrm{Ge} / \mathrm{Cu}$ sublattice arising because of a narrow phase width.

The effect of larger vacancy concentrations has been studied in the systems $\mathrm{SmGe}_{2-x}$ and $\mathrm{GdGe}_{2-x}$ and has identified new vacancy-ordered materials of composition $\mathrm{Sm}_{3} \mathrm{Ge}_{5}$ and $\mathrm{Gd}_{3} \mathrm{Ge}_{5}{ }^{58}$ The former exists in two polymorphs; $\alpha-\mathrm{Sm}_{3} \mathrm{Ge}_{5}$ forms a unique structure $[P \overline{6} 2 c ; c=6.9238(11), c=8.491(3) \AA]$ and $\beta$ - $\mathrm{Sm}_{3} \mathrm{Ge}_{5}$ is isostructural with $\mathrm{Gd}_{3} \mathrm{Ge}_{5}$ and adopt the $\mathrm{Y}_{3} \mathrm{Ge}_{5}$ structure which is itself a vacancy ordered modification of the $\alpha-\mathrm{ThSi}_{2}$ structure. The structure of $\alpha-\mathrm{Sm}_{3} \mathrm{Ge}_{5}$ can be considered to be derived from defective layers of germanium with samarium occupying the interlayer space. The regular removal of $\frac{1}{6}$ of the atoms from the graphene $\mathrm{Ge}$ sheets results in the formation of fused 12-member rings and this reduces the coordination number of samarium from twelve to ten and gives a distorted pentagonal antiprismatic environment. Variation in the stoichiometry of the elemental reagents and indium flux led to the preparation of either the $\alpha$ or $\beta$

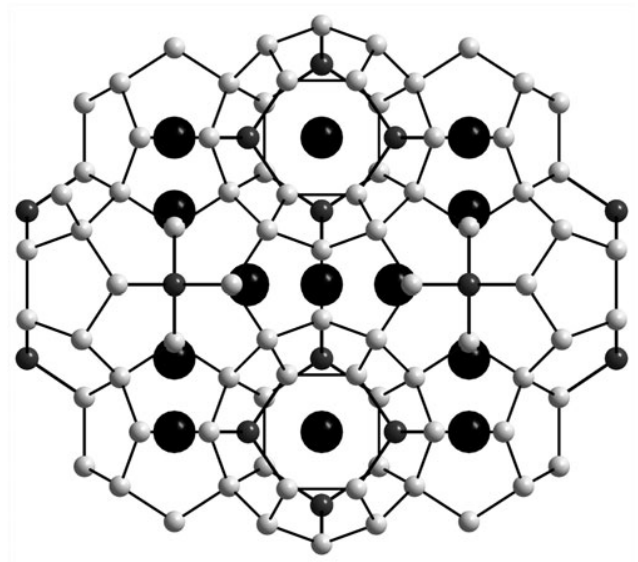

Fig. 5 The type I clathrate structure exhibited by $\mathrm{Ba}_{8} \mathrm{Al}_{13} \mathrm{Si}_{31} \cdot{ }^{56}$ Large black spheres represent barium and smaller spheres represent sites occupied by a mixture of silicon and aluminium. The site that is preferentially occupied by aluminium is shown in dark grey. This structure is also adopted by $\mathrm{Ba}_{8} \mathrm{Cu}_{6-x} \mathrm{Ge}_{40+x} .{ }^{57}$ 
polymorph. The structure of the latter, and of $\mathrm{Gd}_{3} \mathrm{Ge}_{5}$, is composed of threedimensional framework of germanium with the $\mathrm{Sm}^{3+}$ or $\mathrm{Ga}^{3+}$ occupying the irregular hexagonal channels in the framework that exhibits a vacancy ordering pattern that avoids destabilisingly short Ge-Ge separations. All three compounds exhibit a transition to an antiferromagnetically ordered phase at a temperature in the range $10 \leq T / \mathrm{K} \leq 30$.

The ternary phase SrLiSb is isostructural with the calcium analogue and adopts the anti- $\mathrm{PbCl}_{2}$ structure in contrast to the hexagonal symmetry of BaLiSb. Antimony is in nine coordination to four lithium and five strontium atoms giving isolated $\mathrm{Sb}^{3-}$ anions and a diamagnetic Zintl phase. ${ }^{59}$ Three isostructural compounds $A_{2} \mathrm{Ca}_{10} \mathrm{Sb}_{9}\left(A=\left(\mathrm{Li}_{1 / 2} \mathrm{Mg}_{1 / 2}\right),(\mathrm{Mg}),\left(\mathrm{Li}_{0.69} \mathrm{Ca}_{0.31}\right)\right.$ have been reported which contain a $5: 2$ mixture of $\mathrm{Sb}^{3-}$ and $\mathrm{Sb}_{2}{ }^{4-}$ anions. ${ }^{60}$ The structure is rather complex and involves a large range of bonding environments for antimony with between six and nine cation neighbours combined with the presence of $\mathrm{Sb}-\mathrm{Sb}$ dimers. The phase $\mathrm{LiMgCa}_{10} \mathrm{Sb}_{5}\left(\mathrm{Sb}_{2}\right)_{2}$ is an ideal Zintl phase and the physical properties (highly insulating and diamagnetic) support this. Therefore the other two compositions demonstrate modest adjustments in the electron populations being 1 electron rich $\left(\mathrm{Mg}_{2} \mathrm{Ca}_{10} \mathrm{Sb}_{9}\right)$ and 0.4 electrons poor $\left(\mathrm{Li}_{0.69} \mathrm{Ca}_{0.31} \mathrm{Ca}_{10} \mathrm{Sb}_{9}\right)$ per formula unit.

The bonding in $\mathrm{CaMn}_{2} \mathrm{Sb}_{2}$ and $\mathrm{SrMn}_{2} \mathrm{Sb}_{2}$ can also be rationalised as following the Zintl theory of bonding, although these compounds show metallic conductivity and a contribution of the bands arising from the $\mathrm{Mn}$ d-orbitals to the bonding that is incompatible with this. Both phases adopt the $\mathrm{CaAl}_{2} \mathrm{Si}_{2}$ structure with a zig-zag double layer of $[\mathrm{MnSb}]_{2}$ between sheets of alkaline earth metal as shown in Fig. $6 .{ }^{61}$ Strong antiferromagnetic interactions lead to complex magnetic ordering below 250 and $265 \mathrm{~K}$ for $\mathrm{CaMn}_{2} \mathrm{Sb}_{2}$ and $\mathrm{SrMn}_{2} \mathrm{Sb}_{2}$, respectively. A magnetic structure is proposed on the basis of spin polarised calculations that suggest considerable stability results from an antiferromagnetic structure provided by ferromagnetic coupling within each of the sheets within the bilayer and an antiferromagnetic relationship between these two layers.

The compound $\mathrm{TbRhIn}_{5}$ has been studied ${ }^{62}$ as an analogue of the heavy fermion phase $\mathrm{CeRhIn}_{5}$ which shows an unusual combination of magnetic order and superconductivity. $\mathrm{TbRhIn}_{5}$ adopts the $\mathrm{HoCoGa}_{5}$ structure making it isostructural with the Ce analogue and so contains alternating layers of $\operatorname{TbIn}_{3}$ cuboctahedra with

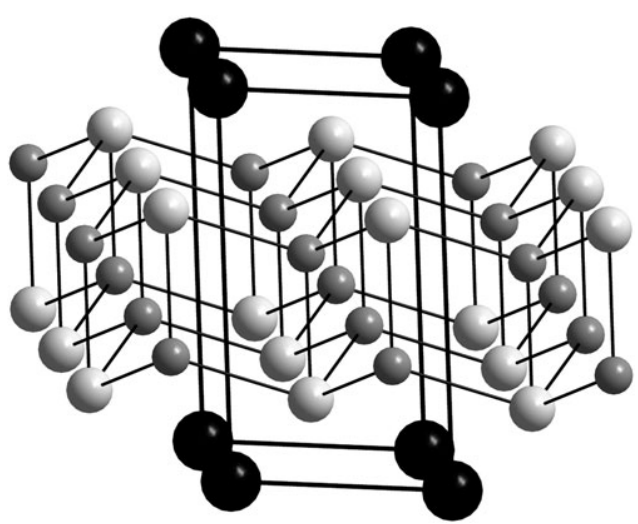

Fig. 6 The structure of $\mathrm{CaMn}_{2} \mathrm{Sb}_{2}$ and $\mathrm{SrMn}_{2} \mathrm{Sb}_{2}$. Light and dark grey spheres represent $\mathrm{Mn}$ and $\mathrm{Sb}$, respectively. The alkaline earth metals are shown as black spheres. ${ }^{61}$ 
$\mathrm{RhIn}_{2}$ rectangular. This material undergoes an antiferromagnetic transition and exhibits a simultaneous discontinuity in the metallic conductivity at $48 \mathrm{~K}$ but does not exhibit superconductivity. The relatively high Néel temperature indicates that the strong coupling of paramagnetic centres via the conduction electrons leads to dominance of the electronic properties by these RKKY interactions and so explains the absence of heavy fermion behaviour.

The stuffed $\mathrm{Mn}_{5} \mathrm{Si}_{3}$ structure exhibited by the compounds $\mathrm{U}_{3} \mathrm{ScSb}_{5}$ and $\mathrm{U}_{3} \mathrm{TiSb}_{5}$ is highly anisotropic and this has a strong impact on the electronic properties of these materials. These compounds contain uranium coordinated to nine antimony atoms to give tricapped trigonal prismatic geometry that reside between chains composed of face-sharing $\mathrm{Sc} / \mathrm{TiSb}_{6}$ octahedra that are aligned along the $c$-direction of the unit cell $\left[P 6_{3} / m c m ; a=9.2145(2), c=6.1938(2) \AA\right] .{ }^{63}$ Although this structure has been observed for a range of compositions it is noteworthy that $\mathrm{U}_{3} \mathrm{ScSb}_{5}$ has the most expanded structure and is the most electron poor member of the series. Both compounds order ferromagnetically at $130 \mathrm{~K}$ and $160 \mathrm{~K}$ for $\mathrm{U}_{3} \mathrm{ScSb}_{5}$ and $\mathrm{U}_{3} \mathrm{TiSb}_{5}$, respectively with the ordered moments aligned along the [120] direction. The coincidence of these magnetic transitions with a large, anisotropic discontinuity in the conductivity illustrates the importance of the conduction electrons in mediating the magnetic exchange interactions.

\section{Halides, chalcogenides, nitrides}

The transition metal oxyhalide $\mathrm{FeTe}_{2} \mathrm{O}_{5} \mathrm{Cl}_{x} \mathrm{Br}_{1-x}$ contains dense layers of edge sharing $\mathrm{FeO}_{6}$ octahedra giving tetrameric units of $\left[\mathrm{Fe}_{4} \mathrm{O}_{16}\right]^{20-}$ which are linked by $\left[\mathrm{Te}_{4} \mathrm{O}_{10} \mathrm{X}_{2}\right]^{6-}$ groups that provide a strong magnetic buffer between the layers. ${ }^{64}$ The halide and the stereoactive lone pair of $\mathrm{Te}^{\mathrm{IV}}$ are projected into the interlayer space and the layers are only weakly connected with their neighbours by van der Waals interactions. The arrangement of $\mathrm{Fe}^{3+}$ ions within the tetrameric units forms a rhomboid composed of two almost equilateral triangles linked via a shared edge. This triangular arrangement, combined with antiferromagnetic coupling within the tetramer, leads to magnetic frustration within the clusters. Consequently Néel temperatures of around $11 \mathrm{~K}$ are observed despite the presence of antiferromagnetic interactions an order of magnitude stronger than this temperature suggests.

The compositions $\mathrm{Rb}_{2} \mathrm{KCrF}_{6}$ and $\mathrm{Rb}_{2} \mathrm{KGaF}_{6}$ adopt the elpasolite structure at room temperature with an ordered arrangement of potassium and chromium or gallium over the octahedral sites of the perovskite parent structure. A single crystal study of both of these compounds has determined that on cooling below room temperature these phases undergo structural transitions. These transitions are driven by a striking increase in the coordination number of some of the $\mathrm{K}^{+}$from six to seven giving a pentagonal bipyramidal arrangement around $80 \%$ of the potassium sites. ${ }^{65}$ Interestingly, this rearrangement does not occur in a cooperative manner, as is commonly observed in perovskites, and instead suggests strong parallels with the structural chemistry of tungsten bronzes.

The compound $\mathrm{Ba}_{4} \mathrm{Ga}_{2} \mathrm{~B}_{8} \mathrm{O}_{18} \mathrm{Cl}_{2} \cdot \mathrm{NaCl}$ forms a remarkable structure which can be related to known framework materials stuffed with $\mathrm{Cl}^{-}$and $\mathrm{NaCl}^{66}$ The structural skeleton is built up from $\mathrm{B}_{4} \mathrm{O}_{9}$ units linked via the four terminal oxide anions to $\mathrm{GaO}_{4}$ giving a three-dimensionally connected network. The channels in this structure are occupied by $\mathrm{Ba}^{2+}, \mathrm{Cl}^{-}$and $\mathrm{NaCl}$. The chloride anion bonded to sodium is precisely located whilst that in a neighbouring tunnel displays considerable positional disorder. This material shows second harmonic generation and the 
observation of disorder in the guest ions suggests that modification by ion-exchange may yield a new route to related inclusion compounds. Crystal structures that can be considered as a composite of the chemical components have also been reported for the family of compounds $\mathrm{Ba}_{2} \mathrm{~F}_{2} \mathrm{SnS}_{3}, \mathrm{Ba}_{2} \mathrm{~F}_{2} \mathrm{SnSe}_{3}, \mathrm{Sr}_{2} \mathrm{~F}_{2} \mathrm{SnS}_{3}$ and $\mathrm{Sr}_{2} \mathrm{~F}_{2} \mathrm{SnS}_{3}$. ${ }^{66}$ The structures of all four compounds are built up from stacking of layers of fluorite $\left[(\mathrm{Ba} / \mathrm{Sr})_{2} \mathrm{~F}_{2}\right]$ and distorted rock salt $\left[\mathrm{Sn}(\mathrm{S} / \mathrm{Se})_{3}\right]$. Crucially the electronic properties of these materials derive from the behaviour of these component parts; the fluorite acts as a charge-donor which is balanced by the charge-acceptor nature of the rock salt layer. The interaction between the layers is thus largely ionic in character.

The homologous series $\mathrm{Sr}_{n+1} M_{n} \mathrm{O}_{3 n-1} \mathrm{Cu}_{2 m} \mathrm{~S}_{m+1}$ is built up from $\mathrm{Cu}_{2} \mathrm{~S}_{2}$ antifluorite layers and $\mathrm{Sr}_{n+1} M_{n} \mathrm{O}_{3 n-1}$ layers that resemble a section of variable thickness from the perovskite structure. ${ }^{67}$ These materials show properties that are associated with both of these parent structures but also permit the tuning of the properties of one layer by adjusting the chemistry of the other. The structures of $\mathrm{Sr}_{2} \mathrm{MnO}_{2} \mathrm{Cu}_{3.5} \mathrm{~S}_{3}$ and $\mathrm{Sr}_{2} \mathrm{MnO}_{2} \mathrm{Cu}_{5.5} \mathrm{~S}_{4}$ show that the $\mathrm{Cu}-\mathrm{S}$ blocks can contain copper disorder that is similar to that observed in the fast-ion conducting phase $\alpha-\mathrm{Cu}_{2} \mathrm{~S}$. Indeed this mobility has been exploited to carry out a reductive topotactic replacement of copper by lithium in $\mathrm{Sr}_{2} \mathrm{MnO}_{2} \mathrm{Cu}_{1.5} \mathrm{~S}_{2}$ and $\mathrm{Sr}_{2} \mathrm{MnO}_{2} \mathrm{Cu}_{3.5} \mathrm{~S}_{3}$ to give $\mathrm{Sr}_{2} \mathrm{MnO}_{2}$ $\mathrm{Li}_{1.86(3)} \mathrm{S}_{2}$ and $\mathrm{Sr}_{2} \mathrm{MnO}_{2} \mathrm{Li}_{3.8(1)} \mathrm{S}_{3}$, respectively. ${ }^{68}$ The parent compounds $\mathrm{Sr}_{2} \mathrm{MnO}_{2^{-}}$ $\mathrm{Cu}_{1.5} \mathrm{~S}_{2}$ and $\mathrm{Sr}_{2} \mathrm{MnO}_{2} \mathrm{Cu}_{3.5} \mathrm{~S}_{3}$ are examples of metamagnets; they are antiferromagnetically ordered in zero applied field below ca. $30 \mathrm{~K}$, but a ferromagnetically ordered phase can be stabilised by application of an appropriately large magnetic field. Magnetic measurements on $\mathrm{Sr}_{2} \mathrm{MnO}_{2} \mathrm{Li}_{3.8(1)} \mathrm{S}_{3}$ show that lithiation, and the associated reduction of $\mathrm{Mn}^{2.5+}$ to $\mathrm{Mn}^{2.2+}$, destroys both the low-field antiferromagnetic and high-field ferromagnetic states. Tetrahedral $\mathrm{CuS}_{4}$ units are also reported in $\mathrm{KCaEr}_{2} \mathrm{CuS}_{5}{ }^{69}$ This compound contains highly localised copper in chains which alternate with $\mathrm{ErS}_{6}$ to give a layered structure with $\mathrm{K}^{+}$and $\mathrm{Ca}^{2+}$ located in 8- and 6-coordinate interlayer sites.

Ion exchange reactions of $\mathrm{K}_{6} \mathrm{Sn}\left[\mathrm{Zn}_{4} \mathrm{Sn}_{4} \mathrm{~S}_{17}\right]$ have provided access to new phases containing $\mathrm{Cs}^{+}$and $\mathrm{NH}_{4}{ }^{+} .{ }^{70}$ The parent material has three types of microporous cavity. The largest of these provides an excellent match in size for $\mathrm{Cs}^{+}$and exchange reactions carried out using a single crystal clearly show that the single Cs atom per formula unit that is exchanged into the structure uniquely occupies this position as shown in Fig. 7. Competitive ion-exchange reactions involving a mixed solution of $\mathrm{CsCl}$ and $\mathrm{RbI}$ showed that this site uniquely selects $\mathrm{Cs}^{+}$, with $\mathrm{Rb}^{+}$being exchanged onto a smaller site in the structure. All three sites are interconnected and the smallest site shows a good selectivity for $\mathrm{NH}_{4}{ }^{+}$which migrates through the larger sites in order to access this thermodynamically preferable position. This strong selectivity for caesium even in low concentrations compared to rubidium and ammonium suggests that this material may find applications in ${ }^{137} \mathrm{Cs}$ recovery from nuclear waste.

$\mathrm{Sr}_{4} \mathrm{GaN}_{3} \mathrm{O}$ and $\mathrm{Sr}_{4} \mathrm{GaN}_{3}(\mathrm{CN})_{2}$ have been prepared from sodium melt at $900{ }^{\circ} \mathrm{C}$ and both contain triangular $\left[\mathrm{GaN}_{3}\right]^{6-}$ unit in slabs of $\left[\mathrm{Sr}_{4} \mathrm{GaN}_{3}\right]^{2+}$ that are packed in a herringbone pattern. ${ }^{71}$ Strontium cations in adjacent slabs are coordinated by either oxide or carbodiimide to form pillared structures. There is considerable positional disorder in the pillaring oxide anion; reflecting the underbonded nature of this environment. The common observation of slabs in these phases suggest that this motif may be useful in the design of related intergrowth structures.

Layered structures have also been reported for the mixed nitride halide phases $\mathrm{Sr}_{2} \mathrm{~N}\left(X, X^{\prime}\right)\left(X, X^{\prime}=\mathrm{Cl}, \mathrm{Br}, \mathrm{I}\right)$. The anti- $\alpha-\mathrm{NaFeO}_{2}$ structure of $\mathrm{Sr}_{2} \mathrm{NI}$ has been 

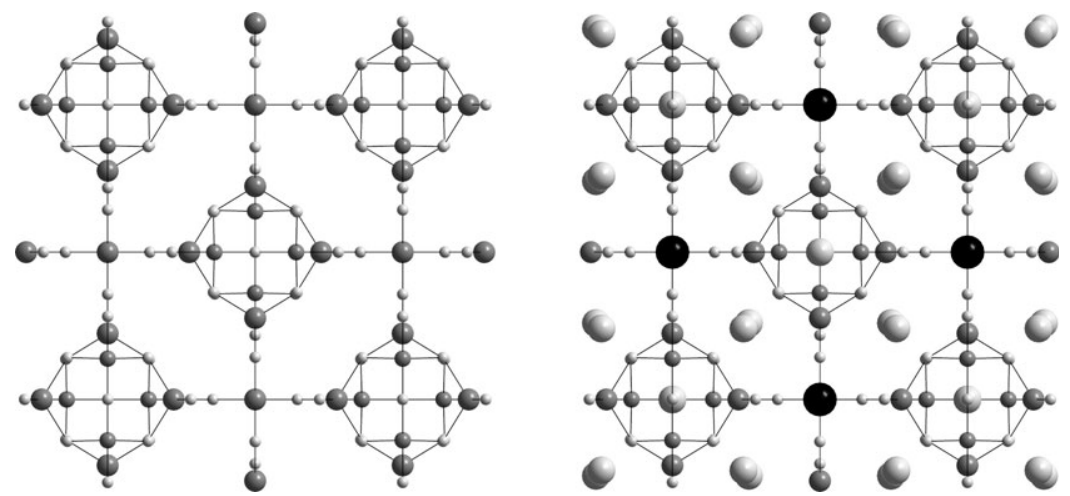

Fig. $7 \mathrm{~K}_{6} \mathrm{Sn}\left[\mathrm{Zn}_{4} \mathrm{Sn}_{4} \mathrm{~S}_{17}\right]$ contains a framework $\left\{\mathrm{Sn}\left[\mathrm{Zn}_{4} \mathrm{~S}_{17}\right]\right\}^{6-}$ illustrated (left) with sulfur represented as light grey spheres and zinc and tin as small and larger dark grey spheres. Exchange of $\mathrm{Cs}^{+}$for one equivalent of $\mathrm{K}^{+}$shows a preference for the largest of the three cation sites giving the structure shown on the right with $\mathrm{Cs}$ and $\mathrm{K}$ represented by large black and light grey spheres. ${ }^{70}$

identified for the first time and the presence of solid solutions between this compound and the isostructural ternary phases $\mathrm{Sr}_{2} \mathrm{NCl}$ and $\mathrm{Sr}_{2} \mathrm{NBr}$ have been established with complete mixing of halides over a single crystallographic site. ${ }^{72}$ All compounds are diamagnetic and insulating. A rock salt structure of $\gamma-\mathrm{Mo}_{2} \mathrm{~N}$ has been proposed and the high pressure treatment of this compound has produced a sample suitable for neutron powder diffraction experiments. These have unambiguously established that the nitride is exclusively located in the octahedral interstitial sites of a face-centred cubic lattice of molybdenum with a disordered distribution of the $50 \%$ vacancies on nitride position. ${ }^{73}$

Single crystals of $\mathrm{MnSiN}_{2}$ have been prepared for the first time by using a slight excess of manganese to permit dissolution of $\mathrm{Si}_{3} \mathrm{~N}_{4}$ in molten manganese under a nitrogen atmosphere and subsequent growth of transparent red crystals from the metallic droplet. ${ }^{74}$ This has permitted a refinement of the structure previously proposed and a thorough investigation of the magnetic properties. The nitride anions form a slightly distorted pseudo-hexagonally close-packed array with an ordered arrangement of $\mathrm{Mn}^{2+}$ and $\mathrm{Si}^{4+}$ over the tetrahedrally-coordinated interstitial sites in the structure to give an orthorhombic phase $\left[P n a 2_{1}\right]$ closely related to wurtzite. Extremely strong antiferromagnetic interactions exist and lead to antiferromagnetic order below a broad transition at $490 \mathrm{~K}$ although the $\mathrm{Mn}^{2+}$ spins remain strongly coupled to at least $700 \mathrm{~K}$. A second magnetic transition at $442 \mathrm{~K}$ is associated with canting of the magnetic moments leading to the emergence of a net magnetisation.

\section{References}

1 P. Karena, A. R. Moodenbaugh, J. Goldberger, P. N. Santhosh and P. M. Woodward, J. Solid State Chem., 2006, 179, 2120.

2 A. C. Mclaughlin, Solid State Commun., 2006, 137, 354.

3 E. J. Cussen, D. R. Lynham and J. Rogers, Chem. Mater., 2006, 18, 2855.

4 E. E. McCabe and C. Greaves, Chem. Mater., 2006, 18, 5774.

5 V. Thangadurai and W. Weppner, J. Solid State Chem., 2006, 179, 974.

6 M. P. O'Callaghan, D. R. Lynham, G. Z. Chen and E. J. Cussen, Chem. Mater., 2006, 18, 4681.

7 E. J. Cussen, Chem. Commun., 2006, 412. 
8 Z. S. Gönen, D. Paluchowski, P. Zavalij, B. W. Eichhorn and J. Gopalakrishnan, Inorg. Chem., 2006, 45, 8736.

9 J.-F. Colin, V. Pralong, V. Caignaert, M. Hervieu and B. Raveau, Inorg. Chem., 2006, 45, 7217.

10 J. Sun, M. Yang, G. Li, T. Yang, F. Liao, Y. Wang, M. Xiong and J. Lin, Inorg. Chem., 2006, 45, 9151.

11 A. C. Mclaughlin, L. Begg, C. Harrow, S. A. J. Kimber, F. Sher and J. P. Attfield, J. Am. Chem. Soc., 2006, 128, 12364.

12 M. A. Hayward, Chem. Mater., 2006, 18, 321.

13 A. Bowman, M. Allix, D. Pelloquin and M. J. Rosseinsky, J. Am. Chem. Soc., 2006, 128, 12606.

14 H. M. Palmer, A. Snedden, A. J. Wright and C. Greaves, Chem. Mater., 2006, 18, 1130.

15 M. L. Ruiz-González, R. Cortés-Gil, J. M. Alonso, A. Hernando, M. Vallet-Regí and J. M. González-Calbet, Chem. Mater., 2006, 18, 5757.

16 M. Giot, P. Beran, O. Pérez, S. Malo, M. Hervieu, B. Raveau, M. Nevriva, K. Knizek and P. Roussel, Chem. Mater., 2006, 18, 3225.

17 J. J. Adkin and M. A. Hayward, J. Solid State Chem., 2006, 179, 70.

18 R. B. Macquart, W. R. Gemmill, M. J. Davis, M. D. Smith and H.-C. z. Loye, Inorg. Chem., 2006, 45, 4391.

19 E. O. Chi, K. M. Ok, Y. Porter and P. S. Halasyamani, Chem. Mater., 2006, 18, 2070.

20 X. Kuang, C. Bridges, M. Allix, J. B. Claridge, H. Hughes and M. J. Rosseinsky, Chem. Mater., 2006, 18, 5130.

21 Y. H. Huang, H. Fjellvåg, M. Karppinen, B. C. Hauback, H. Yamauchi and J. B. Goodenough, Chem. Mater., 2006, 18, 2130.

22 K. Yamaura, Q. Huang, L. Zhang, K. Takada, Y. Baba, T. Nagai, Y. Matsui, K. Kosuda and E. Takayama-Muromachi, J. Am. Chem. Soc., 2006, 128, 9448.

23 Q. Xu, T. Klimczuk, J. Jansen, R. J. Cava and H. W. Zandbergen, Chem. Mater., 2006, 18, 4585.

24 A. A. Belik, T. Wuernisha, T. Kamiyama, K. Mori, M. Maie, T. Nagai, Y. Matsui and E. Takayama-Muromachi|, Chem. Mater., 2006, 18, 133.

25 M. R. Suchomel, A. M. Fogg, M. Allix, H. Niu, J. B. Claridge and M. J. Rosseinsky, Chem. Mater., 2006, 18, 4987.

26 N. Cornei, N. Tancret, F. Abraham and O. Mentré, Inorg. Chem., 2006, 45, 4886.

27 R. Punn, A. M. Feteira, D. C. Sinclair and C. Greaves, J. Am. Chem. Soc., 2006, 128, 15386.

28 J. S. Knyrim, P. Becker, D. Johrendt and H. Huppertz, Angew. Chem., Int. Ed., 2006, 45, 8239.

29 J. Barbier and L. M. D. Cranswick, J. Solid State Chem., 2006, 179, 3958.

30 X. Chen, J. Zuo, X. Chang, Y. Zhao, H. Zang and W. Xiao, J. Solid State Chem., 2006, 179, 3191.

31 F. Kong, S.-P. Huang, Z.-M. Sun, J.-G. Mao and W.-D. Cheng, J. Am. Chem. Soc., 2006, 128, 7750 .

32 K. M. Ok and P. S. Halasyamani, J. Solid State Chem., 2006, 179, 1345.

33 H. Birkedal, A. M. K. Andersen, A. Arakcheeva, G. Chapuis, P. Norby and P. Pattison, Inorg. Chem., 2006, 45, 4346.

34 G. W. Stinton, M. R. Hampson and J. S. O. Evans, Inorg. Chem., 2006, 45, 4352.

35 H. Ettis, H. Naïli and T. Mhiri, J. Solid State Chem., 2006, 179, 3107.

36 S. Benmokhtar, A. E. Jazouli, J. P. Chaminade, P. Gravereau, A. Wattiaux, L. Fournès, J. C. Grenier and D. Waal, J. Solid State Chem., 2006, 179, 3709.

37 J. M. Porras-Vázquez, Á. G. D. L. Torre, D. Maerrero-López, E. R. Losilla and M. A. G. Aranda, Dalton Trans., 2006, 2691.

38 K. M. Ok, J. Baek, P. S. Halasyamani and D. O'Hare, Inorg. Chem., 2006, 45, 10207.

39 M. Yang, J. Yu, J. Di, J. Li, P. Chen, Q. Fang, Y. Chen and R. Xu, Inorg. Chem., 2006, 45, 3588.

40 R. Baies, O. Pérez, V. Caignaert, V. Pralong and B. Raveau, J. Mater. Chem., 2006, 16, 2434.

41 K. G. S. Ranmohotti, X. Mo, M. K. Smith and S.-J. Hwu, Inorg. Chem., 2006, 45, 3665.

42 E. R. Parnham, P. S. Wheatley and R. E. Morris, Chem. Commun., 2006, 380.

43 J. Liang, J. Li, J. Yu, P. Chen, Q. Fang, F. Sun and R. Xu, Angew. Chem., Int. Ed., 2006, $45,2546$.

44 A. Corma, M. J. Díaz-Cabañas, J. L. Jordá, C. Martínez and M. Moliner, Nature, 2006, 443,842 .

45 G. Wang, J. Li, J. Yu, P. Chen, Q. Pan, H. Song and R. Xu, Chem. Mater., 2006, 18, 5637. 
46 S. Georges, F. Goutenoire and P. Lacorre, J. Solid State Chem., 2006, 179, 4020.

47 F. Gramm, C. Baerlocher, L. B. McCusker, S. J. Warrender, P. A. Wright, B. Han, S. B. Hong, Z. Liu, T. Ohsuna and O. Terasaki, Nature, 2006, 444, 79.

48 J. F. Colin, T. Bataille, S. E. Ashbrook, N. Audebrand, L. L. Pollès, J. Y. Pivan and E. L. Fur, Inorg. Chem., 2006, 45, 6034.

49 T. Sivakumar, K. M. Ok and P. S. Halasyamani, Inorg. Chem., 2006, 45, 3602.

50 M. B. Salah, S. Vilminot, G. André, M. Richard-Plouet, T. Mhiri, S. Takagi and M. Kurmoo, J. Am. Chem. Soc., 2006, 128, 7972.

51 E. V. Alekseev, S. V. Krivovichevc, W. Depmeier, T. Armbruster, H. Katzke, E. V. Suleimanov and E. V. Chuprunova, J. Solid State Chem., 2006, 179, 2977.

52 K. M. Ok, M. B. Doran and D. O'Hare, J. Mater. Chem., 2006, 16, 3366.

53 V. Smetana, V. Babizhetskyy, G. V. Vajenine and A. Simon, Angew. Chem., Int. Ed., 2006, 45, 6051 .

54 B. Li and J. D. Corbett, J. Am. Chem. Soc., 2006, 128, 12392.

55 B. Li and J. D. Corbett, Inorg. Chem., 2006, 45, 8958.

56 C. L. Condron, J. Martin, G. S. Nolas, P. M. B. Piccoli, A. J. Schultz and S. M. Kauzlarich, Inorg. Chem., 2006, 45, 9381.

57 S. Johnsen, A. Bentien, G. K. H. Madsen, B. B. Iversen and M. Nygren, Chem. Mater., 2006, 18, 4633.

58 P. H. Tobash, D. Lins, S. Bobev, N. Hur, J. D. Thompson and J. L. Sarrao, Inorg. Chem., 2006, 45, 7286.

59 S. Gupta and A. K. Ganguli, J. Solid State Chem., 2006, 179, 1318.

60 A. K. Ganguli, S. Gupta and J. D. Corbett, Inorg. Chem., 2006, 45, 196.

61 S. Bobev and J. Merz, Inorg. Chem., 2006, 45, 4047.

62 W. M. Williams, L. Pham, S. MaQuilon, M. Moldovan, Z. Fisk, D. P. Young and J. Y. Chan, Inorg. Chem., 2006, 45, 4637.

63 A. Mar, O. Tougait, M. Potel, H. Noël and E. B. Lopes, Chem. Mater., 2006, 18, 4533.

64 R. Becker, M. Johnsson, R. K. Kremer, H.-H. Klauss and P. Lemmens, J. Am. Chem. Soc., 2006, 128, 15469.

65 F. J. Zúñiga, A. Tressaud and J. Darriet, J. Solid State Chem., 2006, 179, 3607.

66 R. K. Li and Y. Yu, Inorg. Chem., 2006, 45, 6840.

67 Z. A. Gál, O. J. Rutt, C. F. Smura, T. P. Overton, N. Barrier, S. J. Clarke and J. Hadermann, J. Am. Chem. Soc., 2006, 128, 8530.

68 O. J. Rutt, G. R. Williams and S. J. Clarke, Chem. Commun., 2006, 2869.

69 H.-Y. Zeng, H. Mattausch, A. Simon, F.-K. Zheng, Z.-C. Dong, G.-C. Guo and J.-S. Huang, Inorg. Chem., 2006, 45, 7943.

70 M. J. Manos, K. Chrissafis and M. G. Kanatzidis, J. Am. Chem. Soc., 2006, 128, 8875.

71 P. M. Mallinson, Z. A. Gál and S. J. Clarke, Inorg. Chem., 2006, 45, 419.

72 A. Bowman, R. I. Smith and D. H. Gregory, J. Solid State Chem., 2006, 179, 130.

73 C. L. Bull, T. Kawashima, P. F. McMillan, D. Machon, O. Shebanova, D. Daisenberger, E. Soignard, E. Takayama-Muromachi and L. C. Chapon, J. Solid State Chem., 2006, 179, 1762.

74 S. Esmaeilzadeh, U. Hålenius and M. Valldor, Chem. Mater., 2006, 18, 2713. 